\title{
Silk sericin and burn wound
}

\author{
Beuy Joob · Viroj Wiwanitkit
}

Received: 20 June 2013/Accepted: 21 June 2013/Published online: 29 June 2013

(c) Springer-Verlag Berlin Heidelberg 2013

\section{Sir,}

The recent report on "Silk sericin and burn wound" is very interesting [1]. Aramwit et al. [1] concluded that "silk sericin is safe and beneficial for burn wound treatment when it is added to silver sulfadiazine cream." It seems that silk can be useful for wound management. However, there are some issues for discussion. First, the problem of allergic reaction to silk sericin should be kept in mind. Sericin is a known allergen [2]. In general, sericin free silk is preferable for the case with allergic problem [3]. Second, the use of silk sericin accompanied with silver sulfadiazine has to further verify for any possible chemical interaction. These two points should be kept in mind and further studied before implementation of using silk sericin for burn wound care.

\section{References}

1. Aramwit P, Palapinyo S, Srichana T, Chottanapund S, Muangman $P$ (2013) Silk sericin ameliorates wound healing and its clinical efficacy in burn wounds. Arch Dermatol Res. doi:10.1007/s00403-013-1371-4

2. Cosmi F, Schiatti R, Ignesti C (1986) Diagnostic study of 5 cases of allergic asthma due to sensitization to silk allergens in textile workers from the Prato area. Quad Sclavo Diagn 22(4):433-440

3. Vlachou C, Thomas KS, Williams HC (2009) A case report and critical appraisal of the literature on the use of DermaSilk in children with atopic dermatitis. Clin Exp Dermatol 34(8):e901e903

B. Joob $(\square)$

Sanitation 1 Medical Academic Center, Bangkok, Thailand

e-mail: beuyjoob@hotmail.com

V. Wiwanitkit

Hainan Medical University, Haikou, China

V. Wiwanitkit

Faculty of Medicine, University of Nis, Nis, Serbia

V. Wiwanitkit

Joseph Ayobabalola University, Ikeji-Arakeji, Nigeria 